\title{
Hepatic iron in dialysed patients given intravenous iron dextran
}

\author{
L W Fleming, D Hopwood, A N Shepherd, W K Stewart
}

\begin{abstract}
Five percutaneous biopsy and 17 necropsy liver specimens were analysed histologically and chemically for iron content in 22 patients receiving dialysis for chronic renal failure, 13 of whom were given intravenous iron-dextran. Brissot scores for assessing histological hepatic iron deposition and chemically measured liver iron concentrations correlated closely. Both variables depended on total cumulative dose of iron, and to a lesser extent, on time since the last dose. Fibrosis (seen in five patients) was minimal and non-specific. Electron microscopic examination showed that there was no generalised damage and confirmed the presence of iron in the hepatocytes in the form of ferritin. High liver iron concentrations, in excess of 1000 $\mu \mathrm{g} / 100 \mathrm{mg}$ dry weight, were seen in two patients. Four others given comparable cumulated amounts (18-23 $\mathrm{g}$ iron) did not have such high concentrations. Plasma ferritin concentrations were high in eight patients, some with and some without fibrosis.

The risk of temporarily high iron deposition in the liver causing damage seemed to be minimal when weighed against the benefit of increased haemoglobin in most of the patients. Intravenous iron treatment merits further evaluation, particularly with the advent of erythropoietin treatment, which requires continuously available iron.
\end{abstract}

Gastrointestinal blood loss can be as much as $10 \mathrm{ml}$ daily in patients receiving dialysis, ${ }^{1}$ in addition to losses in the dialysers and continuous blood sampling, which eventually produces an iron deficiency component to the anaemia of chronic renal failure, unless iron supplementation is given. Controversy continues, however, over the best way to supplement iron.

The high plasma ferritin concentrations seen after intravenous iron dextran treatment in patients given maintenance haemodialysis are temporary, decreasing gradually over several months. ${ }^{23}$ Nevertheless, oral iron supplementation is recommended by most investigators ${ }^{45}$ in preference to intravenous iron treatment, due to fears of potentially harmful iron overload when the intestinal barrier mechanisms are bypassed. The toxicity of intravenous iron in patients receiving dialysis remains equivocal because in most series reported to date the issue has been complicated by giving iron by two or more routes-either by multiple blood transfusions, or orally as well as parenterally. ${ }^{56}$ The toxicity of monitored and controlled intravenous iron dextran treatment has not been conclusively shown. The advent of erythropoietin treatment means that the provision of adequate stores of available iron is needed constantly and the choice of which source to use becomes increasingly important.

Associations between serum ferritin concentrations and tissue iron assessed at necropsy have been reported ${ }^{5}$ in dialysed patients who had received intravenous iron dextran, but there are few reports on this topic and none has compared liver biopsy results with contemporaneous serum ferritin concentrations. In this report liver iron content and plasma iron, transferrin, and ferritin in patients receiving iron dextran in a renal dialysis unit were measured and compared with the histological variables of iron content and liver damage. The primary purpose was to determine if liver damage occurred to an extent which outweighed the benefit of the iron supplementation for anaemia. Because plasma ferritin concentrations can be high in conditions other than iron overload, measurements of the iron content of liver biopsy specimens are said to be the only reliable method of identifying actual iron overload in patients with high circulating ferritin concentrations. ${ }^{7}$

\section{Methods}

Twenty two patients (10 men, 12 women, age range 23 to 70 years, median 46 years) receiving dialysis treatment for end stage chronic renal failure were studied. Seven patients were receiving continuous ambulatory peritoneal dialysis (CAPD) and 15 were receiving maintenance haemodialysis. Nine patients (the seven receiving CAPD and two receiving maintenance haemodialysis) had never received iron supplementation and had been receiving dialysis for between one and 44 months at the time of the study. The patients who received iron had been receiving dialysis for between 15 and 132 months at the time of the study. In five patients liver biopsy samples were taken for analysis after informed consent and in the others tissue samples were obtained at necropsy. A 10-20 mm biopsy core of liver was obtained using a disposable $1.5 \mathrm{~mm}$ internal bore Menghini needle on the day following dialysis or from necropsy tissue. 
For light microscopical examination, tissue was fixed in buffered formalin. Paraffin wax sections were stained by the following techniques: haematoxylin and eosin, reticulin, and Perls's stain for iron. The amount of stainable iron in the liver was scored by the method described by Brissot $e t$ al and the final grade calculated. ${ }^{8}$ Brissot scores were also established for 17 age and sex matched control subjects, who showed no evidence of renal or liver disorder at necropsy. Tissue for electron microscopical examination was fixed in cacodylate-buffered 3\% glutaraldehyde. Thin sections were stained with lead citrate and uranyl nitrate and examined with a JEOL 100 $\mathrm{XC}$ electron microscope at $60 \mathrm{kV}$.

Average weights of wet tissue used for hepatic iron estimation were about $20 \mathrm{mg}$ from necropsy specimens and $5 \mathrm{mg}$ from percutaneous biopsy specimens. These were processed and tissue iron assessed chemically by the methods described by Barry and Sherlock. ${ }^{9}$ The same method of measuring iron concentrations (ICSH recommended method ${ }^{10}$ ) was also used for all plasma iron estimations.

Blood samples taken before dialysis were taken either at the dialysis treatment session before the biopsy or within four weeks of death for estimation of plasma total iron, transferrin, and ferritin. Plasma transferrin was measured by immunodiffusion (M-Partigen immunoplates, Hoechst, West Germany) and total iron binding capacity (TIBC) was calculated assuming the binding of $2 \mathrm{Fe}^{+++}$per transferrin molecule (molecular weight 81000 ). Plasma ferritin was estimated by radioimmunoassay (Travenol, England).

Blood samples for haematological indices were taken after dialysis from the pre-dialyser (arterial) blood line just before disconnection in patients receiving maintenance haemodialysis, and at the end of the first dwell-time of the day in patients receiving CAPD (four exchanges per 24 hours)

Patients were given courses of iron dextran injection BP (Imferon; Fisons, England), in amounts providing either $600 \mathrm{mg}$ elemental iron once monthly for nine months, or $200 \mathrm{mg}$ once weekly for 30 weeks, until 5.4 or $6.0 \mathrm{~g}$ iron had been given. The infusions were temporarily discontinued if plasma iron (monitored before the next infusion was due) rose above $20 \mu \mathrm{mol} / 1$. The infusions were given in $5 \%$ saline over four to five hours during dialysis, into the pre-dialyser blood line. No toxic reactions were seen.

\section{Results}

The causes of death are listed for those patients whose specimens were obtained at necropsy (table 1). No patient died of causes related to iron overload.

Chemically measured liver iron in the nine patients not given intravenous iron was 42 (SD 19) $\mu \mathrm{g} / 100 \mathrm{mg}$ dry weight. This is at the lower end of the reported ${ }^{9}$ reference range of 30 to 140 $\mu \mathrm{g} / 100 \mathrm{mg}$ dry weight for this method. The Brissot grade ranged from nil to II (range of scores 0 to 6 , mean (SD) $2 \cdot 3(2 \cdot 3)$ ) and no fibrosis was seen (table 2).

In the 13 patients given intravenous iron at varying time spans before necropsy or percutaneous biopsy (table 2), the measured liver iron ranged from 28 to 1846 , with all but two below $754 \mu \mathrm{g} / 100 \mathrm{mg}$ dry weight (median 345 $\mu \mathrm{g} / 100 \mathrm{mg}$ dry weight). The highest liver iron of $1846 \mu \mathrm{g} / 100 \mathrm{mg}$ dry weight was found in a patient given $22.0 \mathrm{~g}$ iron from iron dextran over five years, the last dose being seven months before assessment. The other patient with concentrations of $>1000 \mu \mathrm{g} / 100 \mathrm{mg}$ dry weight had been given $23.4 \mathrm{~g}$ iron over 10 years, the last dose 21 months previously, and he had also received blood transfusions. Although both these patients had been good responders to iron supplementation in the past in terms of improved blood haemoglobin concentrations, neither responded well to their last course of iron supplementation. Liver iron did not exceed $2 \%$ of dry weight in any patient.

\section{LIGHT MICROSCOPY}

There was a mild periportal fibrosis in five patients, mostly in those with high iron concentrations in their livers (table 2). There was no evidence of cirrhosis. The biopsy specimens showed no evidence of active

Table 1 Necropsy findings and causes of death

\begin{tabular}{|c|c|c|c|}
\hline \multirow[b]{2}{*}{ Case No } & \multirow[b]{2}{*}{ Renal disease } & \multicolumn{2}{|l|}{ Causes of death } \\
\hline & & Contributory & Immediate \\
\hline 1 & Polycystic kidneys & Recurrent pancreatitis & Septicaemia \\
\hline 2 & Polycystic kidneys & $\begin{array}{l}\text { Left ventricular hypertrophy; hepatic congestion and gross } \\
\text { polycystic change }\end{array}$ & Unexplained postoperative (sacral mass) \\
\hline 3 & Chronic glomerulonephritis & Protein depletion; pleural effusions; hepatic congestion & Multiple pulmonary infarcts \\
\hline 4 & Chronic pyelonephritis & Biventricular hypertrophy; recurrent pancreatitis & Unidentified \\
\hline 5 & Chronic glomerulonephritis & Hypertensive heart disease; hepatic congestion & Myocardial infarction \\
\hline 6 & Obstructive & Left ventricular hypertrophy; obstructive uropathy; peritonitis & Uncertain \\
\hline 7 & Chronic glomerulonephritis & Peritonitis; pelvic abscess & Myocardial infarction \\
\hline 8 & Vasculitic & $\begin{array}{l}\text { Congestive heart failure; hepatic congestion; } \\
\text { pulmonary thrombo-emboli }\end{array}$ & Suppurative bronchopneumonia; \\
\hline 9 & Hypoplasia & Left ventricular hypertrophy; pelvic abscess & Myocardial infarction \\
\hline 10 & Chronic glomerulonephritis & Renal isograft rejection; calcific arteriosclerosis & $\begin{array}{l}\text { Bronchopneumonia associated with } \\
\text { immunosuppression }\end{array}$ \\
\hline 11 & Chronic pyelonephritis & $\begin{array}{l}\text { Mitral stenosis/incompetence; biventricular heart failure; } \\
\text { hepatic congestion }\end{array}$ & Endocarditis; septicaemia \\
\hline $\begin{array}{l}12 \\
13\end{array}$ & $\begin{array}{l}\text { Hypertensive } \\
\text { Hypoplasia }\end{array}$ & $\begin{array}{l}\text { Multiple granulomata; hepatic congestion } \\
\text { Pulmonary emboli }\end{array}$ & $\begin{array}{l}\text { Subarachnoid haemorrhage } \\
\text { Unidentified }\end{array}$ \\
\hline 14 & Chronic glomerulonephritis & Left ventricular hypertrophy; septicaemia & $\begin{array}{l}\text { Rupture of left ventricular abscess; } \\
\text { endocarditis }\end{array}$ \\
\hline 15 & Hypoplasia & Cardiac conduction defect; dysrhythmia; hepatic congestion & $\begin{array}{l}\text { Biventricular heart failure } \\
\text { postoperative parathyroidectomy }\end{array}$ \\
\hline $\begin{array}{l}16 \\
17\end{array}$ & $\begin{array}{l}\text { Hypoplasia } \\
\text { Chronic glomerulonephritis }\end{array}$ & $\begin{array}{l}\text { Left ventricular hypertrophy; aortic valve prosthesis } \\
\text { Peritonitis; pulmonary oedema; effusions; hepatic congestion }\end{array}$ & $\begin{array}{l}\text { Gastroenteritis; hypokalaemia } \\
\text { Apical pneumonia }\end{array}$ \\
\hline
\end{tabular}


Table 2 Chemically measured and histologically assessed liver iron state in dialysed patients receiving intravenous iron

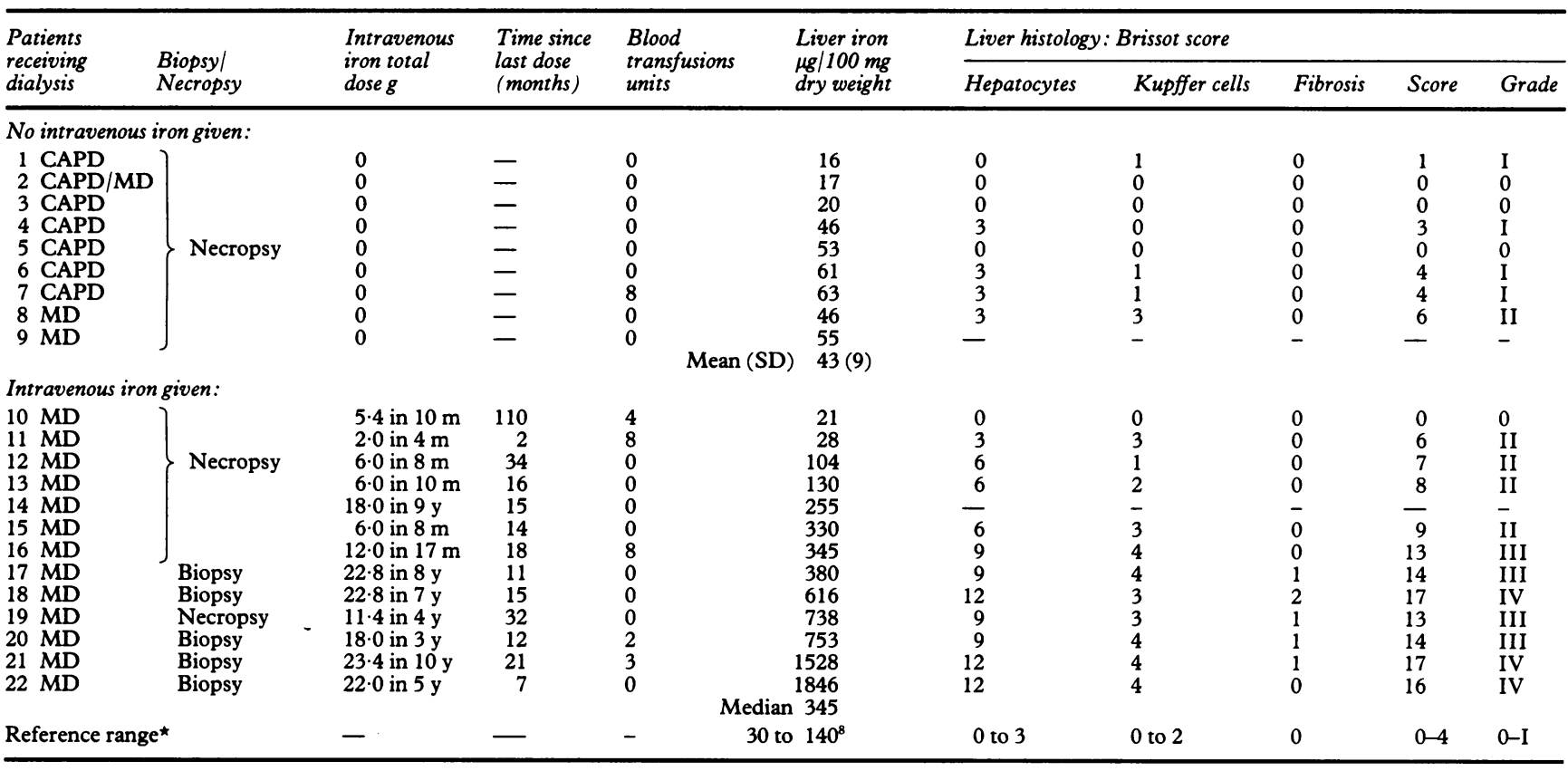

$\star$ Age and sex matched controls without liver or renal disease; $m=$ months; $y=$ years.

damage or degeneration in the hepatocytes, although there was an apparent increase in lipofuscin granules and haemosiderin, especially in those patients with a high liver iron content. The necropsy specimens showed a variety of changes, including small and large cytoplasmic vacuoles. Three of the patients with high liver iron had some double plating of the hepatocytes, suggesting some recent regeneration. Excess mitoses were not seen.

The Kupffer cells were generally increased in number, practically all showing some ferritin or lipofuscin, or both. This was more noticeable in the patients with high iron concentrations in their livers. In some of these latter patients there were scattered aggregates of Kupffer cells and macrophages containing iron (fig 1) in their portal tracts. There was no iron in the bile duct epithelium. Seven patients showed a mild non-specific reactive hepatitis, which followed no particular pattern.

The Brissot grade ranged from II to IV (scores 6 to 17 , mean (SD) $11 \cdot 2(5 \cdot 2)$ ). The Perls stain showed variable iron in hepatocytes and in Kupffer cells. Fibrosis, seen in five patients, was score 1 (minimal) in four patients and score 2 in one patient, extending variably from the portal tracts. Fibrosis was not seen in the patient with the highest chemically measured liver iron (table 2). The fibrosis was seen in the patients with liver iron between 380 and $1528 \mu \mathrm{g} / 100 \mathrm{mg}$ dry weight, given total doses between 11.4 and $23.4 \mathrm{~g}$ iron intra-

Table 3 Correlations between variables related to iron storage

\begin{tabular}{llll}
\hline Variables & $n=$ & $r$ & $p$ Value \\
\hline Hepatic iron/Brissot score & 20 & +0.79 & $<0.001$ \\
Hepatic iron/cumulative iron dose & 22 & +0.78 & $<0.001$ \\
Hepatic iron/cumulative iron dose, patients given iron & 13 & +0.70 & $<0.01$ \\
Brissot score/cumulative iron dose & 20 & +0.92 & $<0.01$ \\
Brissot score/time since last dose & 11 & -0.77 & $<0.01$ \\
Hepatic iron/time since last dose & 12 & -0.29 & $>0.30$ \\
Hepatic/plasma iron & 22 & +0.22 & $>0.30$ \\
Heptic iron/plasma ferritin & 19 & +0.42 & $<0.05$ \\
Hepatic iron/plasma transferrin & 20 & -0.43 & $<0.05$ \\
Plasma iron/plasma ferritin & 19 & +0.63 & $<0.005$ \\
\hline
\end{tabular}

venously over a three to 10 year period, 11 to 32 months before assessment.

\section{ELECTRON MICROSCOPY}

In percutaneous needle biopsy specimens there was little damage to the hepatocytes, confirming results of light microscopy. Iron was seen as electron dense material in the residual bodies in the form of granules with a regular pattern. There was an excess of residual bodies in the livers containing excess iron but the other organelles showed little sign of damage. Ferritin could be seen in the residual bodies. The necropsy specimens had the typical cytoplasm seen after death, but an excess of residual bodies could still be made out in those patients with a high iron content in their livers. At high resolution the ferritin cores were resolved.

\section{CORRELATIONS}

There were significant positive correlations (table 3) between hepatic iron, Brissot score, and cumulative iron dose, and significant negative correlations between Brissot score and time since last dose in the 11 patients treated with iron supplementation. The relation between liver iron and the time interval since last dose (fig 2) indicates a wide individual scatter at equivalent dose loads within 12 to 21 months after the last dose. For example, patients given the highest doses of iron (22-23 g) had hepatic iron concentrations ranging from 380 to 1528 $\mu \mathrm{g} \mathrm{Fe} / 100 \mathrm{mg}$ dry weight.

There was no significant correlation between hepatic iron and plasma iron, ferritin, or transferrin (table 4). Plasma ferritin concentrations in excess of $1000 \mathrm{ng} / \mathrm{ml}$ were seen in six patients who had liver iron concentrations ranging from 345 to $1846 \mu \mathrm{g} / 100 \mathrm{mg}$ dry weight.

The five percutaneous biopsy specimens were performed in patients given the largest cumulative amounts of intravenous iron over the preceding years, in whom anaemia was increasing, to ascertain whether further doses 
Figure 1 Perls's stain of typical liver under light microscopy. Iron can be seen in hepatocytes with a lysosomal distribution.

Iron is also present in

Kupffer cells (arrows).

Groups of Kupffer cells

may be seen both in

sinusoids $(S)$ and portal tracts $(P)$.

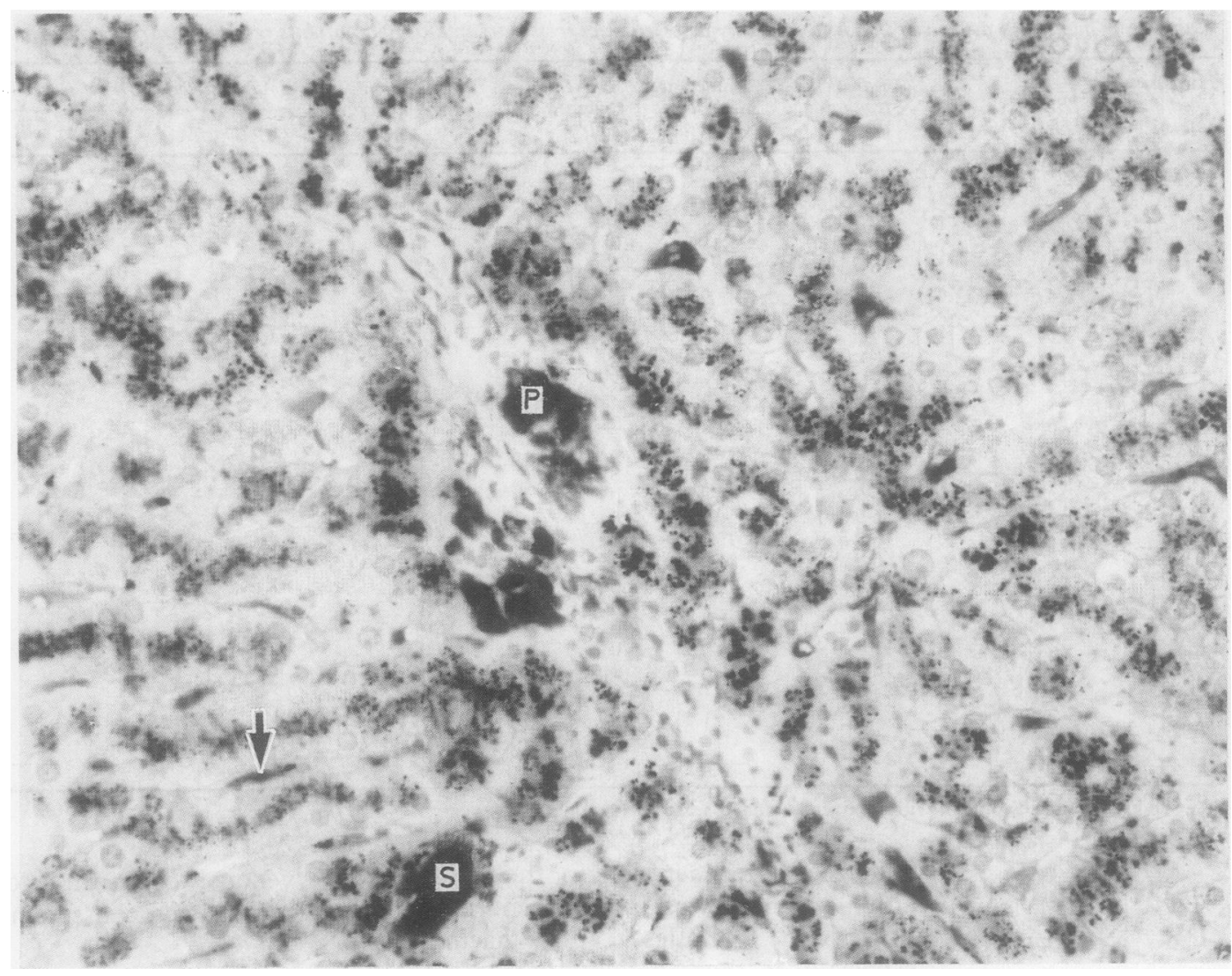

of iron could be justifiably given. For that reason blood haemoglobin concentrations tended to be low at the time of the biopsy (table 4). Two (cases 11 and 16) of the eight necropsy specimens in the group treated with iron supplements were from patients who failed to show a haemoglobin response to previous iron supplementation, and in others a considerable period of time had elapsed since the last dose, which also contributed to low haemoglobin concentrations before death. Most of the patients were normocytic but four of the patients given iron were still macrocytic $(\mathrm{MCV}$
$>96 \mathrm{fl}$ ), and they also had high plasma ferritin concentrations. No patients were hypochromic (table 4).

\section{Discussion}

An understanding of the interrelations between iron storage and liver damage will eventually come from studies of liver iron and histological data in various iron deficient and iron replete conditions. ${ }^{9}$ In this paper we reported the interrelations in dialysed patients given

Table 4 Plasma iron and related concentrations and haematological indices at or near the time of biopsy

\begin{tabular}{|c|c|c|c|c|c|c|c|c|c|}
\hline \multirow[b]{2}{*}{ Case no } & \multicolumn{5}{|l|}{ Plasma } & \multicolumn{4}{|l|}{ Whole blood } \\
\hline & $\begin{array}{l}\mathrm{Fe} \\
\mu \mathrm{mol} / \mathrm{l}\end{array}$ & $\begin{array}{l}\text { TIBC } \\
\mu \mathrm{mol} / \mathrm{l}\end{array}$ & $\begin{array}{l}\text { Saturation } \\
\left(\begin{array}{l}0 \\
0\end{array}\right)\end{array}$ & $\begin{array}{l}\text { Transferrin } \\
(m g / d l)\end{array}$ & $\begin{array}{l}\text { Ferritin } \\
(\text { ng/dl })\end{array}$ & $\begin{array}{l}\text { Haemoglobin } \\
(\mathrm{g} / \mathrm{dl})\end{array}$ & $\begin{array}{l}M C V \\
(f l)\end{array}$ & $\begin{array}{l}M C H \\
(p g)\end{array}$ & $\begin{array}{l}M C H C \\
(g / d l)\end{array}$ \\
\hline \multicolumn{10}{|c|}{ No intravenous iron given: } \\
\hline $\begin{array}{l}1 \\
2 \\
3 \\
4 \\
5 \\
6 \\
7 \\
8 \\
9\end{array}$ & $\begin{array}{r}12 \cdot 0 \\
12 \cdot 7 \\
22 \cdot 0 \\
15.7 \\
6.8 \\
16.3 \\
7.5 \\
=\end{array}$ & $\begin{array}{l}59 \cdot 3 \\
42.0 \\
55 \cdot 7 \\
58 \cdot 2 \\
40 \cdot 0 \\
56 \cdot 8 \\
31 \cdot 0 \\
=\end{array}$ & $\begin{array}{l}20 \\
30 \\
39 \\
27 \\
17 \\
29 \\
24 \\
-\end{array}$ & $\begin{array}{l}240 \\
170 \\
225 \\
236 \\
162 \\
230 \\
126 \\
-\end{array}$ & $\begin{array}{r}10 \\
158 \\
97 \\
274 \\
27 \\
375 \\
258 \\
-\quad\end{array}$ & $\begin{array}{r}13.9 \\
7.3 \\
11.6 \\
9.6 \\
6.6 \\
6.9 \\
7 \cdot 6 \\
7.2\end{array}$ & $\begin{array}{l}92 \\
74 \\
96 \\
92 \\
83 \\
91 \\
95 \\
93 \\
-\end{array}$ & $\begin{array}{l}30 \cdot 9 \\
23 \cdot 9 \\
32 \cdot 2 \\
30.5 \\
27 \cdot 2 \\
31 \cdot 1 \\
30.5 \\
27.9 \\
-\end{array}$ & $\begin{array}{l}33.5 \\
32.3 \\
33.4 \\
32.9 \\
31.7 \\
33.2 \\
31.5 \\
29.6 \\
-\end{array}$ \\
\hline Mean (SD) & $13 \cdot 3(5 \cdot 3)$ & $49 \cdot 0(11 \cdot 2)$ & $26(7)$ & $198(45)$ & $158^{\star}$ & $8 \cdot 8(2 \cdot 7)$ & $89 \cdot 5(7 \cdot 4)$ & $29 \cdot 3(2 \cdot 7)$ & $32 \cdot 3(1 \cdot 3)$ \\
\hline \multicolumn{10}{|c|}{ Intravenous iron given: } \\
\hline $\begin{array}{l}10 \\
11 \\
12 \\
13 \\
14 \\
15 \\
16 \\
17 \\
18 \\
19 \\
20 \\
21 \\
22 \\
\text { Mean (SD) }\end{array}$ & $\begin{array}{r}25.9 \\
19.3 \\
12.2 \\
12.0 \\
8.0 \\
12.5 \\
34.7 \\
12.5 \\
11.6 \\
10.4 \\
35.6 \\
16.5 \\
21.8 \\
17.9(9 \cdot 1)\end{array}$ & $\begin{array}{l}49 \cdot 4 \\
30 \cdot 9 \\
50 \cdot 6 \\
59 \cdot 3 \\
42 \cdot 0 \\
52 \cdot 5 \\
33 \cdot 4 \\
48 \cdot 0 \\
37 \cdot 1 \\
35 \cdot 8 \\
46 \cdot 9 \\
37 \cdot 8 \\
33 \cdot 4 \\
42 \cdot 9 \quad(8 \cdot 9)\end{array}$ & $\begin{array}{l}52 \\
62 \\
24 \\
20 \\
19 \\
24 \\
104 \\
26 \\
31 \\
29 \\
76 \\
44 \\
65 \\
44(26)\end{array}$ & $\begin{array}{l}200 \\
125 \\
205 \\
240 \\
170 \\
213 \\
135 \\
194 \\
150 \\
145 \\
190 \\
153 \\
135 \\
173(36)\end{array}$ & $\begin{array}{r}28 \\
146 \\
292 \\
778 \\
103 \\
>500 \\
7162 \\
-\quad \\
1110 \\
1640 \\
2171 \\
1707 \\
2548 \\
944^{\star}\end{array}$ & $\begin{array}{r}11 \cdot 3 \\
5 \cdot 3 \\
6.9 \\
6.5 \\
11 \cdot 5 \\
11.2 \\
5.0 \\
11.6 \\
7.4 \\
14 \cdot 7 \\
7 \cdot 8 \\
7.4 \\
5.4 \\
8.6(3 \cdot 1)\end{array}$ & $\begin{array}{l}91 \\
78 \\
74 \\
87 \\
80 \\
82 \\
95 \\
97 \\
103 \\
86 \\
97 \\
95 \\
99 \\
89 \cdot 5(9 \cdot 1)\end{array}$ & $\begin{array}{l}30 \cdot 1 \\
26 \cdot 8 \\
24 \cdot 3 \\
26 \cdot 3 \\
25 \cdot 2 \\
27 \cdot 2 \\
33 \cdot 7 \\
32 \cdot 1 \\
33 \cdot 7 \\
28 \cdot 3 \\
34 \cdot 9 \\
31 \cdot 4 \\
33 \cdot 0 \\
29 \cdot 8(3 \cdot 6)\end{array}$ & $\begin{array}{l}33 \cdot 2 \\
32 \cdot 9 \\
32 \cdot 1 \\
30 \cdot 4 \\
31 \cdot 1 \\
32 \cdot 7 \\
33 \cdot 6 \\
33 \cdot 1 \\
31 \cdot 9 \\
33 \cdot 2 \\
34 \cdot 6 \\
33 \cdot 0 \\
32 \cdot 2 \\
32 \cdot 6(1 \cdot 1)\end{array}$ \\
\hline
\end{tabular}


Figure 2 Liver iron concentrations compared with time since last dose.

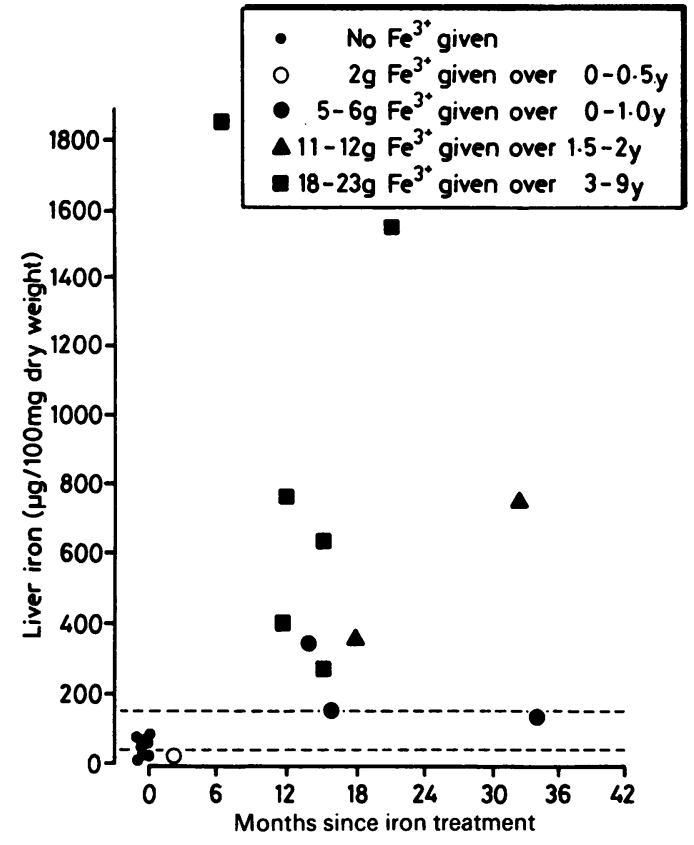

intravenous iron dextran in the treatment of the anaemia of chronic renal disease.

The histological findings were indicative of secondary iron storage, with iron firstly in Kupffer cells and then increasingly in the hepatocytes but not in the bile duct epithelium, with small elements of periportal fibrosis. ${ }^{11}$ The haemosiderin had a typical structure at high resolution. ${ }^{12}$ Such increases can be a nonspecific reactive phenomenon. It has been said that fibrosis or cirrhosis related to iron overload does not occur until more than 2200 $\mu \mathrm{g}$ iron/100 mg dry weight $(2 \cdot 2 \%)$ has been deposited. ${ }^{13}$ None of our patients came into this category. Previous reports on liver changes in patients with renal failure on dialysis given parenteral iron supplements have been similar with iron deposition minimal in the mid-zone, mild fibrosis in a small number of patients, and little evidence of hepatocellular damage. ${ }^{14}$ Others found very little correlation and wide variation between hepatocyte and Kupffer cell iron grades in patients with renal failure given multiple blood transfusions and no iron supplements. ${ }^{16}$ Kupffer cell increase with iron deposition may well represent an early storage phase.

There have been several attempts to relate chemically estimated iron content of the liver to the amount of iron shown histochemically. ${ }^{817-19}$ The earliest attempt graded only the iron detectable in parenchymal cells. Later investigators reported difficulties using this assessment, because only grades III and IV were associated with a significant increase in iron concentration. ${ }^{18}$ Brissot et al tried to overcome these shortcomings by additionally taking into account iron deposits in the reticuloendothelial system (Kupffer cells) and the presence or absence of fibrosis, and weighting each of these observations to give a total score. $^{8}$ They recommended liver biopsy as the only definitive way of obtaining a precise measurement of iron stores. The close correlation between chemically measured liver iron concentrations and Brissot score in our patients was similar to their results ${ }^{8}$ and so supports the validity of either of these estimations when used alone in assessing iron stores in patients with chronic renal failure receiving dialysis treatment as well as in the patients with various liver diseases. ${ }^{89}$ Iron state assessed by Brissot score correlated more closely than chemically measured iron with both the time since last dose and the total iron load.

Gokal et al assessed necropsy tissue iron on a simple 0 to $4+$ scale, and in their series "gross iron loading" was described in patients dialysed for more than three years and given 6 to $25 \mathrm{~g}$ iron as intravenous iron dextran. ${ }^{4}$ The number of blood transfusions given was not stated, other than "72 units" given to one patient. All but three of our patients given iron had been receiving haemodialysis for more than three years, these three receiving treatment for 15, 23, and 29 months, respectively, and our results indicate less iron deposition than that found in the patients studied by Gokal et al. Blood transfusion was minimal in our patients: in four liver iron concentrations were normal, and in all but two of the rest the iron stores were only moderately raised ( 255 to $753 \mu \mathrm{g} / 100 \mathrm{mg}$ dry weight) despite doses of intravenous iron between 6 and $22 \cdot 8 \mathrm{~g}$ over the years. The scatter of results indicates that in at least some of the patients, use of the iron stored after administration of iron dextran had taken place. In the patients given up to $6 \mathrm{~g}$ of iron, there was little or no indication of overload, and in case 17 given $22.8 \mathrm{~g}$ and case 14 , given $18 \mathrm{~g}$, the increased iron stores were moderate. Both these patients were consistently good responders to iron treatment in terms of increased blood haemoglobin concentrations. In contrast, the two patients with the highest liver iron content did not respond well to their most recent course of iron dextran. Within these two extremes the correlation between a poor peripheral blood haemoglobin response and liver iron deposition was more variable.

Fibrosis was found histologically in only one of a reported series of 22 dialysed patients treated with iron ${ }^{4}$ and in five of ours. In another series mild portal fibrosis was seen in six of 26 non-dialysed patients with renal failure and in three of 14 dialysed patients given up to $100 \mathrm{~g}$ elemental iron in the course of blood transfusion or iron dextran treatment. ${ }^{15}$ In our patients fibrosis was minimal in four patients, and it is noteworthy that the grade 2 fibrosis seen in one patient occurred with a liver iron of $616 \mu \mathrm{g} \mathrm{Fe} / 100 \mathrm{mg}$ dry weight and not in the two patients with liver iron above $1000 \mu \mathrm{g} / 100 \mathrm{mg}$ dry weight. Fibrosis can be trivial with massive transfusional overload. ${ }^{9}$ In contrast, heavy fibrosis has been found in haemochromatotic patients with liver iron concentrations in the 1.6 to $2.6 \%$ dry weight range ${ }^{8}$ and in siderotic patients with liver iron content above $2 \%(2000$ $\mu \mathrm{g} / 100 \mathrm{mg}$ dry weight). ${ }^{20}$ The lack of correlation between fibrosis and iron load suggests that fibrosis can be caused by other factors in each of these situations.

It has been suggested that transfusional iron may be less prone to cause liver damage than iron absorbed through the gut. ${ }^{21}$ Others suggest 
that the iron from iron dextran is potentially more harmful and less available than transfusional iron. ${ }^{4}$ Our results, overall, do not support this. The two patients with the highest liver iron have been receiving maintenance haemodialysis for 103 and 118 months, respectively, and are among our longest treated patients. Although their plasma ferritin concentrations were also high and exceeded $1000 \mathrm{ng} / \mathrm{ml}$, similar or higher plasma ferritin concentrations were seen in three other patients. Neither of these patients had HLA antigens A3, B7, or B14. Their high liver iron was not therefore associated with the presence of histocompatibility enzymes linked to idiopathic haemochromatosis, adding weight to the evidence that these antigens are not relevant to the iron overload state in dialysed patients. $^{22}$

Liver iron values in transfusional iron overload are very much higher ${ }^{23}$ than those seen in our patients, ranging from 1.4 to $4.9 \%$ with a mean of $2.2 \%(2200 \mu \mathrm{g} / 100 \mathrm{mg}$ dry weight $){ }^{23}$ Focal portal fibrosis and inflammation were present in seven of these 10 patients ${ }^{23}$ and early cirrhosis was present in one. These were all non-thalassaemic patients with normal renal function and various anaemias, who had received between 60 and 210 units of transfused blood. Serum ferritin concentrations in these patients were also higher than in our series, with nine of 15 patients having values of $2000 \mathrm{ng} / \mathrm{ml}$ or more.$^{23}$ Most transfused patients with thalassemia have liver iron values between 1.5 and $5.5 \%{ }^{24}$ Hepatic iron concentrations between 3000 and $10000 \mu \mathrm{g} / 100 \mathrm{mg}$ dry weight $(3 \%$ to $10 \%)$ have been seen in other patients receiving multiple blood transfusions. ${ }^{18}$ None of our patients exceeded $2 \%$ and only two were above $1 \%$

Previous studies have indicated that plasma ferritin values decrease towards normal over a period of months after iron supplementation is discontinued. ${ }^{25}$ The correlation between plasma ferritin and liver iron was less close in our patients than in other series. ${ }^{4}$ Poor correlation between chemical or histochemical indices of hepatic iron stores and plasma indices of iron state has been noted before in several conditions ${ }^{7}$ and is particularly relevant to patients receiving dialysis.

In conclusion, iron deposition in the liver after iron supplementation is to be expected, and the increased deposition found in our patients was not out of line with expectations. The risk of damage from the iron deposition seems low, particularly when weighed against the benefit in terms of increased blood haemoglobin in most patients. The minimal fibrosis noted in a few patients may not necessarily be related to the treatment. The results indicate that fears about intravenous iron dextran administration may be unwarranted when it is used under carefully monitored conditions. The intravenous route should not be ruled out as a method of choice for maintenance of adequate iron stores during erythropoietin treatment. In view of the rapidity with which some dialysed patients use up iron stores under these circumstances the intravenous route may have substantial advantages over the oral route, ${ }^{26}$ including elimination of compliance difficulties and ease of administration.

1 Frei U, Wilks MF, Boehmer S, et al. Gastrointestinal blood loss in haemodialysis patients during use of a lowmolecular-weight heparinoid anticoagulant. Nephrol Dial Transplant 1988;3:435-9.

2 Gokal R, Weatherall DJ, Bunch C. Iron induced increase in red cell size in haemodialysis patients. $Q \mathrm{~J} \mathrm{Med} 1979$; 48:393-401.

3 Fleming LW, Saleem AKN, Goodall HB, Stewart WK. Bone marrow iron and plasma ferritin in dialysed patients given intravenous iron dextran. Clin Lab Haematol 1984;6:23-32.

4 Gokal R, Millard PR, Weatherall DJ, Callender STE, Ledingham JGG, Oliver DO. Iron metabolism in haemodialysis patients. $Q J$ Med 1979;48:369-91.

5 Ali M, Rigolosi R, Fayemi AO, Braun EV, Frascino J, Singer $R$. Failure of serum ferritin to predict bone-marrow iron content after intravenous iron-dextran therapy. Lancet 1982;i:652-5.

6 Murray JA, Slater DN, Parsons MA, Fox M, Smith S, Platts MM. Splenic siderosis and parenteral iron dextran in maintenance $1984 ; 37: 59-64$.

7 Valberg LS, Ghent CN, Lloyd DA, Frei JV, Chamberlain MJ. Diagnostic efficacy of tests for the detection of iron overload in chronic liver disease. Can Med Assoc J 1978;119:229-36.

8 Brissot P, Bourel M, Herry D, et al. Assessment of liver iron content in 271 patients: A re-evaluation of direct and indirect methods. Gastroenterology 1981;80:557-65.

9 Barry M, Sherlock S. Measurement of liver-iron concentration in needle-biopsy specimens. Lancet $1971 ; \mathbf{i}: 100-3$

10 International Committee for Standardisation in Hematology (Iron Panel). Recommendations for measurements of serum iron in human blood. Br J Haematol 1978;38:291-4.

11 Patrick RS, McGhee JO. Biopsy pathology of the liver. London: Chapman and Hall, 1980.

12 Weir MP, Sharp GA, Peters TG. Electron microscopic studies of human haemosiderin and ferritin. J Clin Pathol 1985;38:915-18.

13 Bassett ML, Halliday JW, Powell LW. Value of hepatic iron measurements in early hemochromatosis and determination of the critical iron level associated with fibrosis. Hepatology 1986;6:24-9.

14 Ali M, Fayemi AO, Rigolosi R, Frascino J, Marsden T, Malcolm D. Hemosiderosis in haemodialysis patients. An Malcolm D. Hemosiderosis in haemodialysis patien.

15 Kothari T, Swamy AP, Lee JCK, Mangla JC, Cestero RVM. Hepatic hemosiderosis in maintenance RVM. Hepatic hemosiderosis in mainte

16 Van de Vyver FL, Vanheule AO, Verbueken AH, et al. Patterns of iron storage in patients with severe renal failure. Contr Nephrol 1984;38:153-66.

17 Scheuer FJ, Williams R, Muir AR. Hepatic pathology in relatives of patients with haemochromatosis. J Pathol Bacteriol 1962;84:53-64.

18 Walker RJ, Miller JPG, Dymock IW, Shilkin KB, Williams $R$. Relationship of hepatic iron concentration to histochemical grading and to total chelatable body iron in chemical grading and to total chelatable body iron in conditions

19 Barry M. Liver iron concentration, stainable iron, and total body storage iron. Gut 1974;15:411-5.

20 Bothwell TH, Isaacson C. Siderosis in the Bantu. Br Med J 1982;i:522-4.

21 Cappell DF, Hutchison HE, Jowett M. Transfusional siderosis: The effects of excess iron deposits on the tissues. J Pathol Bacteriol 1957;74:245-64.

22 Maher ER, Curtis JR. Serum ferritin in haemodialysis patients: Is there a relationship to "haemochromatosis alleles" HLA A3, B7, B14? Nephron 1986;43:43-4.

23 Schafer AI, Cheron RG, Dlahy R, et al. Clinical consequences of acquired transfusional iron overload in adults. $N$ Engl J Med 1981;304:319-24.

24 Risdon RA, Barry M, Flynn DM. Transfusional iron overload: The relationship between tissue iron concentration and hepatic fibrosis in thalassaemia. J Pathol 1975; 116:83-95.

25 Fleming LWW, Stewart WK. Serum ferritin concentration after intravenous iron-dextran. Lancet 1982;i:1017-8.

26 Macdougall IC, Hutton RD, Cavill I, Coles GA, Williams JD. Poor response to treatment of renal anaemia with JD. Poor response to treatment of renal anaemia with
erythropoietin corrected by iron given intravenously. erythropoietin corrected by 